\title{
Schaffen Sie Platz für Neues!
}

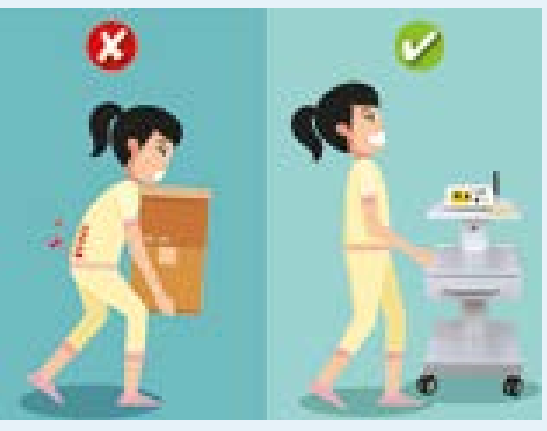
unnötige Zeit. Um zusätzlichen Platz zu schaffen, eigenen sich daher besondere Gerätewagen, wo Geräte aufgebaut bleiben und direkt zur Behandlungseinheit in Patientennähe geschoben werden können. Die Integra Cart De Luxe-Linie aus dem Hause Hager \& Werken bietet für jedes Bedürfnis ein spezielles Cart. Die Multifunktionswagen sind durch ihre hochwertigen Metallausrüstungen äußerst robust und verfügen über 3 Trays (z. B. für
Kleingeräte). Das obere Tray ist mit einem Handgriff versehen. Das mittlere lässt sich stufenlos verstellen. Alle Carts sind mit 3 Steckdosen, 1 Druckluftanschluss und 1 Stromanschluss versehen. Sie verfügen über leicht laufende, feststellbare, antistatische Rollen für schnelles und einfaches Verschieben der Einheit. Beim Modell Integra Cart De Luxe II ist das mittlere Tray mit einer rollengelagerten Materialschublade ausgestattet. Das Modell Integra Cart De Luxe III ist mit 2 Materialschubladen ausgestattet. Die Schubladendeckel sind als Tray ausgearbeitet und lassen sich somit automatisch als Ablage eines Gerätes nutzen. Ebenfalls ist es durch das Integra Anbautray möglich, die Behandlungseinheit zu erweitern. Das Tray lässt sich elegant und einfach an alle Aufbaustangen montieren und ist durch seine 2 Drehgelenke schwenkbar.

Nach einer Pressemitteilung der Hager \& Werken GmbH \& Co. KG, Duisburg 